\title{
ISOENZIMAS NA IDENTIFICAÇÃO PRECOCE DE HÍBRIDOS E CLONES NUCELARES NO MELHORAMENTO DE CITROS (')
}

\author{
ROSA MARIA LIZAৃANA BALLLVE (2.9), RITA BORDIGNON ("), \\ HERCULANO PENNA MEDINA FILHO (2.5), WALTER JOSE SIQUEIRA (2.5), \\ JOAQUIM TEÓFILO SOBRINHO (?) \& JORGINO POMPEU JÚNIOR(")
}

\section{RESUMO}

Um dos problemas relacionados ao melhoramento de citros é a poliembrionia e a conseqüente dificuldade, após cruzamentos controlados, de distinguir clones nucelares dos híbridos. Estudou-se um método para eletroforese de isoenzimas em gel de amido para doze sistemas isoenzímicos, desenvolvendo-se procedimento apropriado para a resolução simultânea dos sistemas fosfatase ácida, peroxidase anódica e catódica, glutamato oxaloacético transaminase, fosfoglucoisomerase, fosfoglucomutase e enzima málica. Caracterizaram-se por esses sistemas 31 clones de citros com possível interesse para o programa de melhoramento do IAC. Estão envolvidos 7 locos e 25 elelos, permitindo uma identificaçäo precoce de híbridos antes do plantio no campo para avaliações agronômicas. Implicaçöes desses estudos básicos no melhoramento e na determinaçāo da taxa de seedlings nucelares de porta-enxertos comerciais säo discutidas.

Termos de indexação: citros, genética, melhoramento, isoenzimas, híbridos, clones nucelares, embriōes zigóticos.

\section{ABSTRACTS \\ ISOZYMES IN THE EARLY IDENTIFICATION OF HYBRIDS AND NUCELLAR CLONES IN CITRUS BREEDING}

One of the problems related to citrus breeding is the polyembryony and the ensuing difficulty in distinguishing nucellar clones from hybrids obtained from controlled crosses. Twelve isozyme systems using starch gel electrophoresis were studied. A procedure for simultaneous resolution of acid phosphatase, anodic and cathodic peroxidase, glutamate oxaloacetate transaminase, phosphoglucoisomerase, phosphoglucomutase and malic enzyme was developed. Thirty one clones with possible use in the Instituto Agronômico de Campinas,

(3) Recebido para publicaçăo em 6 de aogosto de 1990 e aceito em 30 de março de 1991.

(2) Seçāo de Genética, Instituto Agronômico (IAC), Caixa Postal 28, 13001 Campinas (SP).

(3) Estaçäo Experimental Dr. Sylvio Moreira, IAC.

(4) Seçāo de Citricultura, IAC.

(9) Com bolsa de pesquisa do CNPq.

( $)$ Com bolsa CAPES/NNICAMP. 
State of São Paulo, Brazil breeding program were characterized. Seven loci and twenty five alleles are involved allowing for an early identification of hybrids before transplanting them into the field for agronomic evaluations. Implications in breeding strategies and in the determination of the degree of nucellar embryony of commercial rootstocks are discussed.

Index terms: citrus, genetics, breeding, isozymes, hybrids, nucellar clones, zygotic embryos.

\section{INTRODUÇÃO}

O Brasil é o maior produtor de citros e o maior exportador de suco concentrado de laranja do mundo. Entre as frutíferas, os citros ocupam, em escala mundial, o segundo lugar em produção, logo após a uva (FAO, 1988).

Um programa de melhoramento de citros utilizando atécnica de eletroforese foi recentemente iniciado no Instituto Agronômico, tendo por objetivo a diversificaçāo de porta-enxertos e a obtençāo de novos clones de laranjas e tangores com características desejáveis para industrializaçăo e exportaçāo in natura.

Diversos são os problemas associados ao melhoramento de citros. Trata-se de uma espécie perene, de longo ciclo reprodutivo, longo período de juvenilidade e ocorrência generalizada de poliembrionia (CAMERON \& FROST, 1968; SOOST \& CAMERON, 1975).

Em conseqüência da poliembrionia, surge a dificuldade de identificaçāo das plantas híbridas originadas de cruzamentos controlados. As progênies, por via de regra, constituem-se numa mistura de híbridos e de clones nucelares idênticos ao progenitor feminino. Essa identificaçáo é tradicionalmente feita no campo através da análise de caracteres morfológicos. Tal procedimento é demorado, dispendioso e incerto. Grande número de plantas tem que ser mantido no campo até a primeira frutificaçāo, para o reconhecimento dos híbridos, o que é extremamente difícil, principalmente quando tais híbridos resultam de cruzamentos entre clones morfologicamente semelhantes. Seria de grande conveniência que se fizesse esse reconhecimento ainda no estádio de seedlings, antes do plantio no campo. Atualmente, o método mais promissor de identificaçāo precoce de híbridos de citros é através da análise de padróes isoenzímicos obtidos por eletroforese (IGLESIAS et al., 1974; TORRES et al., 1978b, 1982; MOORE \& CASTLE, 1988; ROOSE, 1988; ROOSE \& TRAUGH, 1988).

Essa técnica vem sendo também bastante utilizada em estudos com outras espécies frutíferas, como identificaçāo de híbridos de pêssego (PARFITT et al., 1985; ARULSEKAR et al., 1986) e mamão (MANSHARDT \& WENSLAFF, 1989); como marcadores isoenzímicos em abacate (TORRES et al., 1978a), noz (ARULSEKAR et al., 1985) e uva (LOUKAS et al., 1983), e para caracterizaçāo de cultivares de damasco (BYRNE \& LITTLETON, 1989), morango (BRINGHURST 
et al., 1981), maçã (WEEDEN \& LAMB, 1985), amêndoa (HAUAGGE et al., 1987) e ameixa (BYRNE \& LITTLETON, 1988). Outras aplicaçōes potenciais e exemplos práticos em genética e melhoramento de plantas são conhecidas (TANKSLEY et al., 1981, 1982; MEDINA FILHO, 1983).

Devido às inúmeras variações nos equipamentos, sistemas e condiçōes de laboratório que influenciam os resultados dessas investigaçōes, a técnica de eletroforese deve ser estudada de maneira a adequá-la às condiçōes $a$ aos interesses específicos. Para tanto, pesquisaram-se aspectos relativos ao método, como condiçōes de eletroforese, sistemas isoenzímicos e tipos de tecidos vegetais, para que pudessem ser utilizados na caracterizaçāo de vários clones e híbridos de citros de interesse no referido programa de melhoramento. Os resultados dessas investigaçōes sāo relatados neste trabalho.

\section{MATERIAL E MÉTODOS}

Os clones utilizados no desenvolvimento deste trabalho fazem parte do Banco de Germoplasma do IAC, localizado na Estação Experimental Dr. Sylvio Moreira, em Cordeirópolis, SP. No quadro 1, esses clones são apresentados de acordo com a classificaçāo botânica de TANAKA (1954).

Estudaram-se as principais variaçōes que influenciam a qualidade e resoluçáo de bandas em eletroforese, destacando-se aquelas relativas ao gel de amido, aos tecidos apropriados, à preparação das amostras vegetais e sistemas isoenzímicos. $O$ equipamento e os procedimentos laboratoriais utilizados encontram-se detalhados em TANKSLEY (1979) e MEDINA FILHO \& BALLVE (1989).

Para a preparaçăo do gel, utilizou-se amido hidrolisado de batata (Sigma), numa concentraçāo de $11,9 \%$, determinada previamente, e soluçāo tampão inicial contendo $2,5 \%$ de TRIS $0,015 \mathrm{M} \mathrm{e} \mathrm{2,5 \%} \mathrm{de} \mathrm{ácido} \mathrm{cítrico} \mathrm{0,036} \mathrm{M.} \mathrm{Foram} \mathrm{testados}$ diversos valores de $\mathrm{pH}$ do gel no jntervalo 7,5 a 8,5, obtidos com o aumento da concentração de TRIS ou citrato, avaliando-se o efeito na resolução e migração de bandas em diversos sistemas isoenzímicos.

Quanto às amostras vegetais, foram testadas folhas de plantas adultas em diversos estádios de desenvolvimento e os padrōes obtidos, comparados com aqueles observados em cotilédones e folhas do primeiro, segundo e terceiro pares em seedlings originados dessas plantas adultas. Esses tecidos foram macerados em soluçāo de extratores contendo diversas combinaçōes e concentraçōes de antioxidantes como sacarose, ácido ascórbico e glutateona reduzida, comparando-se os resultados com os obtidos com a maceraçāo feita em soluçāo TRIS pH 7,5 ou simplesmente água destilada. Para auxiliar o processo de maceraçāo, foi testada também a adiçāo de sílica lavada como abrasivo. 
QUADRO 1. Clones estudados de porta-enxertos e de copas e seus genótipos para sete locos isoenzímicos

Clones

Intro-

duçăo Aps-1 Me-1 Got-1 Got-2 Pgi-1 Pgm-1 Prx -1

Portn-enxertos

(C. aurantium) Laranja-

azeda Sáo Paulo

(C. limonia) Limäo-cravo

Limoira

235 CC II SS FM/MM WS FS FS

(C. reshni) Cleópatra ........

(C. sunki) Sunk

(Poncirus trifoliata)

Trifoliata Davis A

Copes

(C. sinensis) Laranjas-doces

\begin{tabular}{|c|c|c|c|c|c|c|c|c|}
\hline Hamlin & 602 & CC & $\|$ & SS & $\mathrm{F} / \mathrm{MM}$ & FS & FS & $\mathbf{F F}$ \\
\hline Lima graúda .................... & 1587 & $\mathrm{cC}$ & II & SS & $F \mid / M M$ & FS & FS & FF \\
\hline 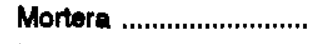 & 84 & CC & II & SS & $\mathbf{F} / \mathbf{M M}$ & FS & FS & FF \\
\hline Natal & 321 & $\mathrm{cc}$ & \| & ss & FI/MM & FS & FS & FF \\
\hline 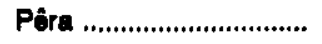 & RGO43 & $\mathrm{CC}$ & $\|$ & SS & FI/MM & FS & FS & FF \\
\hline 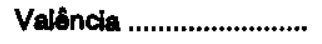 & 716 & $\mathrm{CC}$ & ॥ & SS & $\mathrm{Fl} / \mathrm{MM}$ & FS & FS & FF \\
\hline Valŝncia folha murcha .. & RC004 & $\mathrm{CC}$ & ॥ & SS & $\mathrm{FI} / \mathrm{MM}$ & FS & FS & $\mathbf{F F}$ \\
\hline Westln ............................ & 231 & $\mathrm{cc}$ & II & SS & $\mathrm{F} 1 / \mathrm{MM}$ & FS & FS & $F F$ \\
\hline Carvalhaes ....................... & 732 & $\mathrm{CC}$ & \|I & SS & FI/MM & FS & $\mathbf{F I}$ & FF \\
\hline 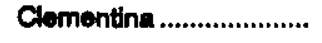 & 288 & $\mathrm{CC}$ & ॥ & SS & $\mathrm{FI} / \mathrm{MM}$ & WS & FI & FF \\
\hline 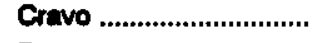 & 313 & CC & $\|$ & Ss & $\mathbf{F l} / \mathbf{M M}$ & FS & $\mathbf{F I}$ & $\mathbf{F M}$ \\
\hline 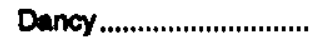 & 351 & $\mathrm{CC}$ & II & SS & FF/MM & FF & FF & $\mathbf{F M}$ \\
\hline 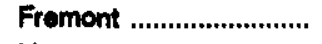 & 741 & $\mathrm{CC}$ & II & SS & FF/MM & FS & $\mathbf{F}$ & FF \\
\hline 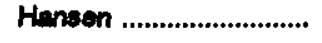 & 1507 & $C C$ & "I & SS & $F F / M M$ & Ws & FF & $\mathbf{F F}$ \\
\hline 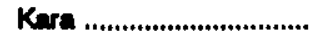 & 392 & CC & \| & Ss & FF/MM & FF & FS & FM \\
\hline 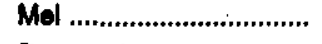 & 260 & $\mathrm{CC}$ & II & SS & $\mathbf{F l} / \mathbf{M M}$ & FS & FS & $\mathbf{F F}$ \\
\hline 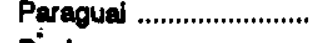 & $\cdot$ & $\mathrm{CC}$ & II & SS & FF/MM & FS & FS & FF \\
\hline 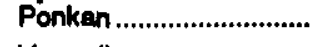 & 380 & $\mathrm{CC}$ & ॥ & SS & FFMM & FF & FF & MM \\
\hline Vermetha ............................ & $*$ & cc & ॥ & Ss & FF/MM & FS & FI? & $\mathbf{F M}$ \\
\hline (C. nobilis) Kng ................ & - & $\mathrm{CC}$ & II & SS & FF/MM & FF & FF & MM \\
\hline $\begin{array}{l}\text { (C. unshiu) Satsuma ....... } \\
\text { Híbridos }\end{array}$ & 438 & $c c$ & II & Ss & $\cdots$ & FS & FF & FF \\
\hline Tangerina Lee ................. & 427 & CC & II & SS & FFMM & FS & $\mathbf{F}$ & FF \\
\hline Tangor Murcote .............. & RGo0s & CC & \| & ss & FF/MM & FF & FF & FF \\
\hline Tangelo Nova .................. & 1583 & $\mathrm{CC}$ & II & SS & FF/MM & FS & FI & FF \\
\hline Tangerina Osceola ........ & 429 & $\mathrm{cc}$ & II & SS & FF/MM & -- & -- & FF \\
\hline
\end{tabular}


Foram pesquisados doze sistemas isoenzímicos: ADH (álcool desidrogenase); G6PDH (glucose-6-fosfato desidrogenase); PGl (fosfoglucoisomerase), PGM (fosfoglucomutase); GOT (glutamato oxaloacético transaminase); PRX (peroxidase); APS (fosfatase ácida); EST (esterase); MDH (malato desidrogenase); ME (enzima málica), SKDH (ácido shikímico desidrogenase); 6PGDH (6-fosfogluconato desidrogenase), e IDH (isocitrato desidrogenase). As soluçōes de revelação para esses sistemas são especificadas em SHAW \& PRASAD (1970) e VALLEJOS (1983).

Investigaçōes iniciais em relação à voltagem e amperagem mostraram que, para um período de inserçāo das amostras de 25 minutos, usando-se nos eletrodos soluçāo de ácido bórico $0,3 \mathrm{M}, \mathrm{pH} 8,3$ ajustado com $\mathrm{NaOH} 4 \mathrm{~N}$, bons resultados sāo obtidos aplicando-se um máximo de $25 \mathrm{~mA}$, sem ultrapassar $150 \mathrm{~V}$. Após a remoçāo das amostras, dos resíduos e do excesso de extrato aderido ao gel, manteve-se um máximo de $150 \mathrm{~V}$ por aproximadamente 60 minutos, período noqual a amperagem se reduz para cerca de $12,5 \mathrm{~mA}$. Esta é então reajustada para $30 \mathrm{~mA}$, resultando num máximo de $300 \mathrm{~V}$. Essa voltagem, mantida por duas horas e meia, promove a migração do fronte para o ânodo em cerca de $8,0 \mathrm{~cm}$ da origem. A posiçāo das bandas relativa à migraçăo do fronte é referida na porçāo anódica do gel com valores positivos de Rf (migraçāo da banda/migraçāo do fronte) e negativos quando as bandas se localizam na porção catódica. Em geral, os valores de Rf para isoenzimas em eletroforese de gel de amido estão sujeitos a pequena variaçāo, influenciada principalmente pelo pH do gel e pela distância de migraçāo do fronte. Nas condiçōes metodológicas especificadas neste trabalho, tais valores são, no entanto, bem constantes.

Cada sistema isoenzímico foi estudado quanto à estabilidade e qualidade da resoluçāo de bandas em relaçāo às variaçōes metodológicas, aos diversos tecidos e às condiçōes de preparação das amostras. Posteriormente, para aqueles que se mostraram promissores, determinaram-se as condiçōes apropriadas que permitissem que o mesmo gel fosse revelado para diversos sistemas. Após definido o método e os sistemas mais indicados, os clones selecionados, como de interesse para o plano de melhoramento, foram caracterizados quanto aos padróes de isoenzimas.

\section{RESULTADOS E DISCUSSĀO}

\subsection{Método da eletroforese}

De acordo com a resolução, distinguem-se, nos limites metodológicos investigados, três grupos de isoenzimas. No primeiro, encontram-se $M D H, G D H$, SKDH e IDH, sistemas de atividade estável, porém de resolução difusa, não se visualizando bandas. $O$ segundo grupo inclui $A D H, E S T$ e 6PGDH. Apesar de estes 
sistemas apresentarem bandas nítidas, com boa resolução, a atividade enzímica é, no entanto, bastante instável, parecendo ser afetada por fatores ambientais e/ou interaçōes complexas não determinadas. No terceiro grupo, mais promissor para as condiçōes testadas, constam PGI, GOT, APS, PRX, PGM e ME, sistemas de expassão estável com resolução de bandas nítidas. Para esses sistemas, procurou-se otimizar o método.

Variaçōes de $\mathrm{pH}$ do gel resultaram em diferenças quanto à resolução e migração relativa das bandas. Verificou-se para PGI, APS e ME, que o aumento do $\mathrm{pH}$ resultou apenas em menor migraçāo relativa ao fronte, sem, porém, alterar significativamente a resolução. PRX anódica apresentou bandas de resoluçāo difusa acompanhando as principais, fenômeno conhecido como modificaçāo pós-traduçāo. Com pH menor que 8,0, esse fenômeno é mais intenso, dificultando a interpretação dos géis. PRX catódica mostrou alteração na expressão e na migração relativa entre as bandas. Em pH maior que 8,3, algumas bandas migram muito próximas e com pH menor que 7,9, bandas adicionais são resolvidas. Esses efeitos sāo mais bem evidenciados quando ocorre maior migração do fronte. Para PGM, o pH limite é 8,3, pois valores maiores resultam em géis de pouca atividade e com bandas de alguns genótipos migrando muito próximas. GOT mostrou-se bastante dependente do $\mathrm{pH}$. Em pH abaixo de 8,0, verifica-se que a banda de menor migraçáo é resolvida no cátodo e que uma das bandas da regiāo distal do ânodo subdivide-se em três, fato aindasob investigação, porém sem resultados conclusivos.

Esses testes indicaram que, utilizando-se $\mathrm{pH}$ entre 8,0 e 8,3, os sistemas PGI, PGM, GOT, APS, PRX e ME são revelados apropriada e simultaneamente numa mesma corrida, apresentando bandas estáveis, nítidas e com separação adequada.

Com relaçāo aos diversos extratores testados, verificou-se que o melhor deles foi a água destilada, adicionando-se $0,2 \mathrm{ml}$ a $60 \mathrm{mg}$ de tecido vegetal. Nenhuma outra solução extratora se apresentou vantajosa em relação à água destilada, nem mesmo para aqueles sistemas que se mostraram insatisfatórios, referidos no primeiro e segundo grupos. 0 emprego de $7 \mathrm{mg}$ de sílica lavada como abrasivo facilitou sobremaneira a operação de maceração, sem alterar a qualidade do gel.

\subsection{Tecidos pesquisados}

Quanto aos tecidos estudados, verificou-se não haver diferenças nos padrōes isoenzímicos de folhas em diversos estádios de desenvolvimento, provenientes de plantas adultas. $O$ mesmo se observou em relação às folhas dos seedlings nucelares que apresentaram exatamente os mesmos padrōes das plantas adultas que thes deram origem. As folhas dos seedlings constituem, portanto, material ideal para análises de isoenzimas visando à identificação precoce de híbridos. 
As análises revelaram que as folhas, uma vez destacadas, umedecidas, acondicionadas em sacos plásticos e armazenadas em geladeira $\left(10^{\circ} \mathrm{C}\right)$, mantêm a atividade enzímica e seus padróes inalterados durante quatro semanas. Isso permite uma flexibilidade operacional das análises laboratoriais das plantas mantidas em localidades distantes.

Os seedlings analisados originaram-se de sementes das quais foram removidas a testa e o tegumento, germinadas em placas de Petri com papel de filtro umedecido e, posteriormente, numeradas e transplantadas para bandejas tipo speedling. Idealmente, seria desejável que a análise isoenzímica fosse feita anteriormente a essa operação de transplante e identificação das plantas a serem analisadas. Para tanto, tentou-se utilizar parte dos cotilédones dos embriōes em início de germinaçāo, quando ainda nas placas de Petri. Embora apresentassem boa resolução para diversos sistemas, a remoçāo de parte desse tecido de resenva do embriāo compromete bastante a sobrevivência dos seedlings, principalmente nos casos em que os cotilédones são de reduzido tamanho. $O$ tecido de cotilédone não se mostrou, portanto, apropriado para tal objetivo.

\subsection{Análises isoenzímicas}

Utilizando-se folhas de plantas adultas, estudaram-se 31 clones do Banco de Germoplasma, alguns híbridos em fase de seedling de trifoliata 'Davis A' com laranja-azeda 'São Paulo' e com tangerina 'Sunki', bem como seedlings de limāo-cravo 'Limeira' obtidos por livre polinizaçāo. Na figura 1 estāo representados, esquematicamente, os alelos e seus respectivos Rfs para os sistemas isoenzímicos e no quadro 1, os genótipos correspondentes a cada clone.

ME - Segundo TORRES et al. $(1982,1985)$, esse sistema apresenta duas regiōes de resolução. Uma delas, próxima ao fronte, denominada Me-2, é de pouca coloraçāo e sem variabiliade em Citrus. A outra, de coloraçāo intensa, foi identificada como loco Me-1 codificando para uma enzima monômera. Cinco alelos foram descritos: F, I, M, S e R. Os alelos M e S ocorrem em condiçāo heterozigota (MI) em limăo-rugoso (Citrus jambhiri) e (SI) em lima (Citrus aurantifolia). O alelo $\mathrm{R}$ foi encontrado somente em clones de Poncirus trifoliata em estado heterozigoto (FR). $O$ alelo F, além de Poncirus, foi encontrado também em cidras (Citrus medica). O alelo 1 é de distribuiçăo generalizada, sendo homozigotas as laranjas, as tangerinas e a laranja-azeda (Citrus aurantium).

Nas condiçōes do presente trabalho, a regiāo do loco Me-2 não foi observada, somente Me-1, no qual se verificou o genótipo II para todo o germoplama com exceção de Poncirus trifoliata clone 'Davis A', o qual é homozigoto RR (Figura 2). Ele se mostrou diferente dos sete clones analisados por TORRES et al. (1982), todos FR. O clone 'Davis A', como é distinto dos demais, torna-se de relativa valia no programa de melhoramento. Me-1 serve, portanto, como um bom 
marcador nos cruzamentos em que o 'Davis A' é utilizado como genitor feminino, uma vez que, sendo homozigoto RR e os demais clones de porta-enxertos II, nucelares e híbridos deverăo ser facilmente distinguíveis.

APS - Na porçáo anódica do gel, APS se expressa em três regióes. Com Rf 0,95 próximo ao fronte, existe nessa regiāo uma banda de resolução nítida, porém instável, nem sempre se expressando. Nas ocasiōes em que foi observada, essa banda se localizou na mesma posição para todos os clones estudados.

$\mathrm{Na}$ segunda regiăo, de Rf 0,77, encontra-se uma banda nítida, de coloração intensa e expressáo uniforme presente em todos os clones estudados, exceto no trifoliata 'Davis A', que nāo apresenta banda alguma nessa regiāo. Em cruzamentos desse clone com tangerina 'Sunki' e com laranja-azeda, os híbridos, identificados por Got-1, também foram reconhecidos facilmente por APS, porquanto todos eles apresentaram essa banda. Nos seedlings nucelares, à semelhança do 'Davis A', ela está ausente. Tais obsenvaçöes sugerem que essa Rf

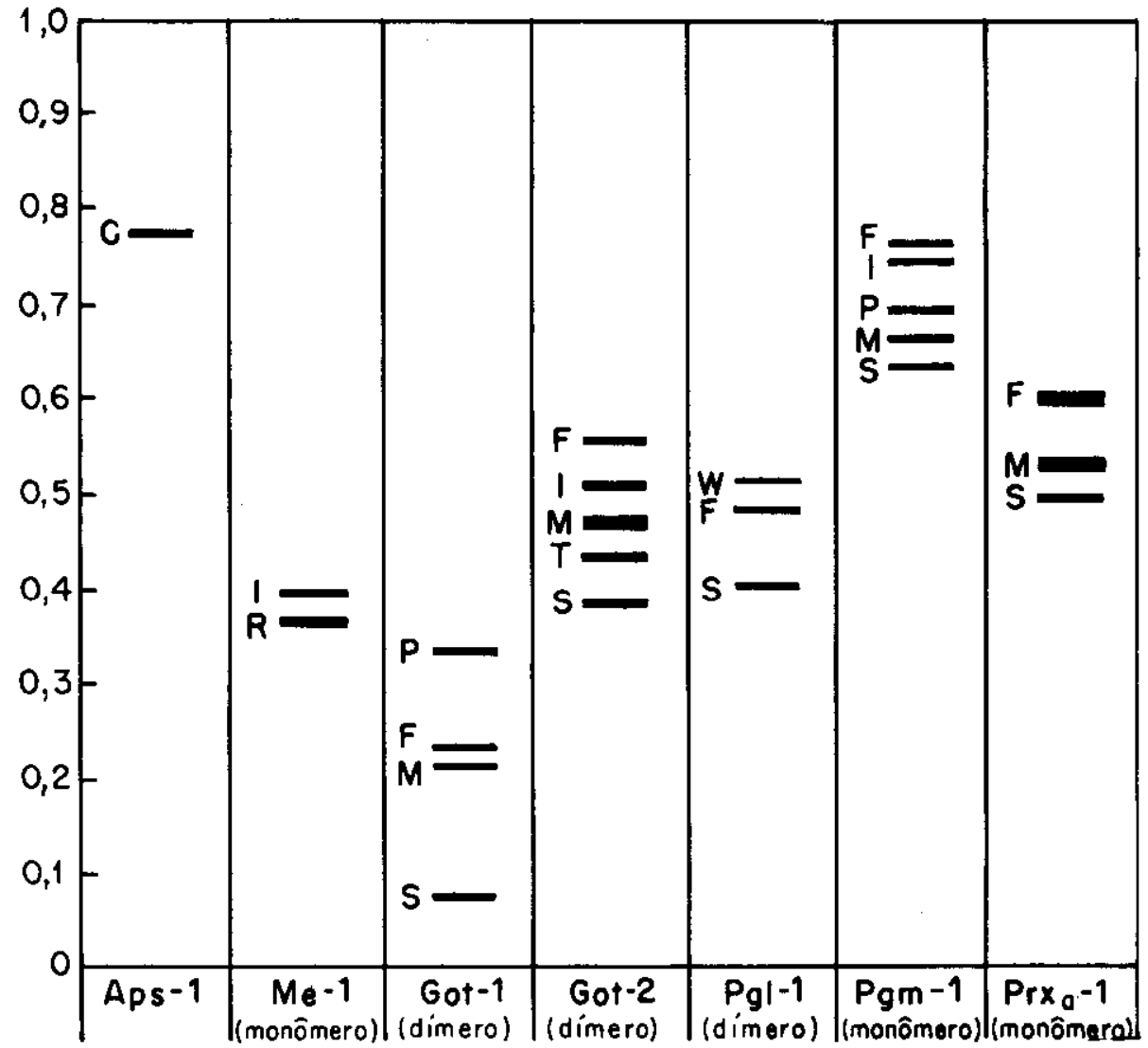

FIGURA 1. Representaçäo esquemática dos alelos de sete locos isoenzímicos e seus respectivos Ris. Entre parênteses é indicada a estrutura quaternária da isoenzima. 

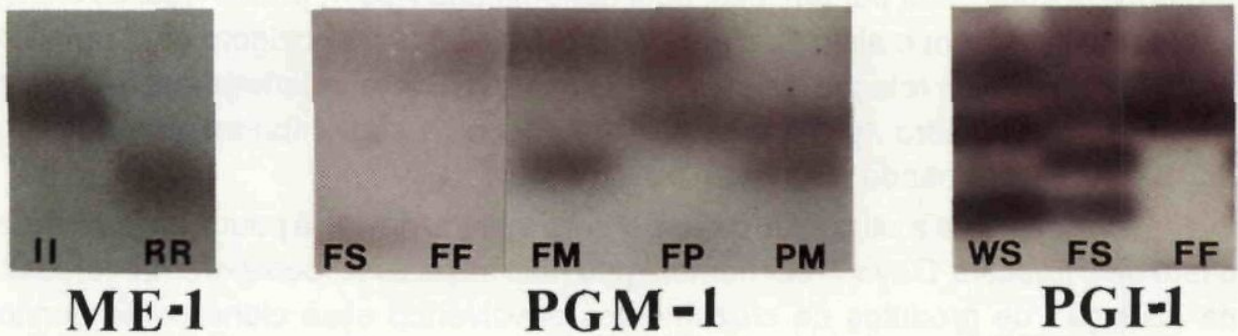

$M E-1$ PGM-1
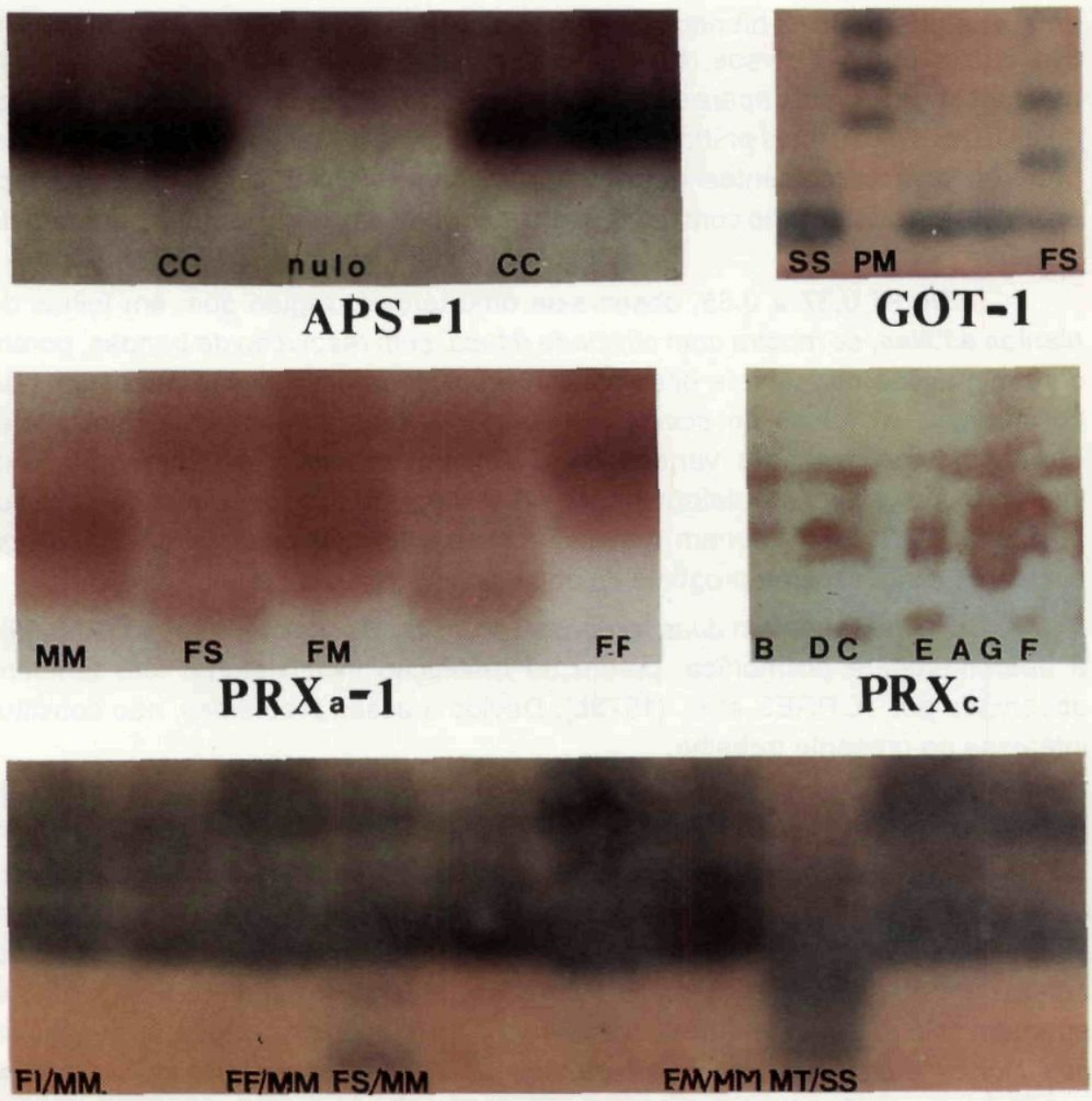

\section{GOT-2}

FIGURA 2. Zimogramas de citros em gel de amido. Genótipos de sete locos isoenzímicos e padröes de PRX catódica. 
regiāo seja codificada por um loco, aqui denominado Aps-1, para o qual os clones estudados possuem o alelo $\mathrm{C}$, e $P$. trifoliata 'Davis $\mathrm{A}$ ' é homozigoto para um alelo nulo, recessivo em relaçāo ao alelo $C$. Tangerina 'Sunki' e laranja-azeda seriam homozigotos CC para Aps-1, uma vez que todos os seus híbridos com trifoliata apresentam essa banda (Figura 2).

Apesar de a utilizaçáo de Aps-1 ser pequena devido à pouca variabilidade, o fato de o trifoliata 'Davis A'ser homozigoto nulo torna esse loco extremamente útil na distinçāo de produtos de cruzamentos envolvendo esse clone como genitor feminino. Neste caso, o caráter trifoliata, dominante, nãotem utilidade discriminativa, uma vez que tanto os híbridos como os nucelares apresentam folhas trifoliadas. Em cruzamentos inversos, isto é, utilizando-o como genitor masculino, esse marcador morfológico, aparentemente homozigoto no 'Davis A', seria, sem dúvida, de utilização muito mais prática. Casos existem em que, apesar disso, pode-se dar preferência a cruzamentos desse trifoliata como genitor feminino, como, por exemplo, em hibridaçōes com tangerina 'Sunki', devido ao seu pequeno número de sementes.

De Rf 0,37 a 0,55 , observa-se uma terceira regiāo que, em folhas de plantas adultas, se mostra com atividade difusa, sem resoluçăo de bandas, porém com migraçōes certamente diferentes. A resolução dessa regiāo em tecidos de cotilédones e folhas de seedlings de até 30 dias apresenta-se bem nítida, observando-se evidente variabilidade. A caracterizaçāo dessa regiáo, sua interpretaçāo genética e determinaçāo de seu potencial como marcador, nāo foi realizada. Para tanto, seriam necessários estudos dos padrōes em seedlings nucelares e zigóticos na progênie de cada clone.

$P G \mid$ - É visto em duas regiōes. A primeira, de major migração $(R f 0,60)$, é aparentemente polimórfica, porém de resoluçāo insatisfatória, fato também observado por TORRES et al. (1978b). Devido a esses problemas, nāo constitui interesse no presente trabalho.

A segunda regiāo, codificada por $P g i-1$, foi estudada por TORRES et al. (1978b, 1985; SOOST \& TORRES (1981); MOORE \& CASTLE (1988) e ROOSE \& TRAUGH (1988), tendo sido descritos os alelos $W$ (Rf 0,51$), F(R f 0,48)$ e $S$ (Rf $0,40)$ e $P(R f<0,40)$. O W foi encontrado em $C$. aurantium (laranja-azeda), C. limon (limōes verdadeiros) e $C$. reticulata (tangerinas), tipicamente em condição heterozigota, associado a $S$ ou $F$, ocorrendo, porém, em condiçāo homozigota apenas no clone 'Willowleaf' de $C$. aurantium. Com relaçăo a esse loco, os genótipos dos clones estudados encontram-se no quadro 1. Desses clones, doze são mencionados na literatura: limäo-cravo, Cleópatra, Sunki, laranja-azeda, Valência, Clementina, Mel, Dancy, King, Kara, Ponkan e Satsuma. Neste trabalho, confirmaram-se os seus genótipos e a natureza dimérica dessa isoenzima pela ocorrência de heterodímeros em individuos heterozigotos. Uma confirmação 
adicional do dimerismo dessa enzima foi obtida em géis de grãos de pólen de clones heterozigotos. Nesses, nāo se observaram os heterodímeros, mas somente os dois homodímeros.

Verificou-se que, no germoplasma analisado, três foram os genótipos de Pgi-1 encontrados: FS, FF e WS (Figura 2). O potencial de utilizaçäo desse loco na distinçăo de clones nucelares e híbridos é dependente dos genótipos dos clones envolvidos em cada cruzamento especifico, variando de 0 a $100 \%$. Nas seis possíveis combinaçōes entre os genótipos desse germoplasma, o potencial, independente da direçāo dos cruzamentos, é indicado entre parêntesis: FS x FS $(50 \%)$; FS XFF (50\%); FS XWS (75\%); FF XFF (0\%); FF xWS (100\%) e WS X WS $(50 \%)$. Por exemplo, em cruzamentos FF $x$ WS, todos os híbridos serăo FW ou FS, enquanto os nucelares terão o genótipo materno, distinto dos híbridos. Neste caso, identificam-se, portanto, $100 \%$ dos híbridos obtidos. Em cruzamentos FS $x$ FS, metade dos híbridos terá o genótipo FS, indistinguível dos clones nucelares, sendo, portanto, reconhecíveis, por esse loco apenas $50 \%$ dos híbridos.

PGM - São conhecidos dois locos para essa enzima: Pgm-2, de migração catódica, expressa-se em tecidos do floema efoi estudado por ROOSE \& TRAUGH (1988). Em tecidos de folha, observa-se somente a expressão do loco Pgm-1, de migraçāo anódica e codificando para uma enzima monômera. TORRES et al. (1978b) descreveram cinco alelos: $F$ (Rf 0,76), I (Rf 0,74), P (Rf 0,68), M (Rf 0,65) e $S$ (Rf 0,63), ocorrendo todos também no germoplasma analisado no presente trabalho nas combinaçōes FI, FS e PM. Padrōes de indivíduos dos genótipos FS, $F F$, FM, FP e PM são mostrados na figura 2. Dos clones estudados, aqueles doze comuns aos caracterizados por TORRES et al. (1978b) tiveram seus genótipos confirmados, à exceção da tangerina 'King'e do limāo-cravo.

A tangerina 'King', que deveria ser FS, na análise deste trabalho mostrou ser FF. Essa 'King' foi introduzida da Califórnia e é, provavelmente, produto de recombinação. O limāo-cravo 'Limeira', de ampla utilizaçăo como porta-enxerto no Estado de São Paulo, também parece ser produto de origem zigótica. É homozigoto $F F$, enquanto a introduçäo 519 , bem como o 'Rangpur Lime', analisado por TORRES et al. (1978b), é de genótipo FI.

Com os genótipos observados (FF, Fl, FS e PM), sāo possíveis dez diferentes combinaçōes de cruzamentos. O potencial desse ioco na identificação de híbridos varia de 0 (FF x FF) a 100\% (FF, FI e FS x PM), independente da direçăo do cruzamento.

GOT - Duas são as regiōes observadas e identificadas por TORRES et al. (1978b). Em Got-1, próximo à origem, ocorrem quatro alelos codificando para uma enzima dímera de Rf 0,36 (P), 0,25 (F), 0,23 (M) e 0,06 (S). Alelos M e P ocorrem em Poncirus, Fortunella e outros gêneros, enquanto $\mathrm{F}$ e $\mathrm{S}$ são comuns a Citrus. 
No germoplasma analisado, esses quatro alelostambém estão presentes, sendo $P$. trifoliata PM, limāo-cravo FS $\Theta$ os demais, todos SS (Figura 2). Embora a resoluçāo seja de excelente qualidade e os alelos, de migraçāo bastante distinta, a utilização deste loco como marcador fica restrito a cruzamentos envolvendo Poncirus ou limāo-cravo, uma vez que os demais são SS. A segregação deste loco em indivíduos oriundos por autofecundaçāo do limāo-cravo 'Limeira' é absolutamente normal para proporçāo mendeliana de 1FF : 2FS : 1SS $\left(\chi^{2}=1,29 n s\right)$.

Got-2, na porçăo mediana do gel, apresenta em Citrus os alelos $F, M, S$ e T. Um provável novo alelo, aqui denominado I, tem migração intermediária entre $F$ e $M$, estando presente apenas nas laranjas-doces e na tangerina 'Cravo (Quadro 1).SOOST \& TORRES (1982) se referem a Got-2 como um loco duplicado responsável por un a enzima dimérica com formaçāo de heterodímero somente intraloco.

De acordo com a hipótese de um loco duplicado com formação de heterodímero intraloco, os genótipos dos clones sāo listados no quadro $1 \mathrm{e}$ mostrados na figura 2. No presente trabalho, a interpretação dos genótipos de Got-2 dos diversos clones não é definitiva por razōes discutidas a seguir.

SOOST \& TORRES (1982) apresentaram como evidência da hipótese de um loco duplicado que a progênie de autofecundaçāo de tangerina 'Clementina' (FF/ $M M)$, com padrão de duas bandas, não segregava. Na presente investigaçāo, da mesma forma que 'Clementina', a tangerina 'Sunki' tem para Got-2 idêntico padrāo de duas bandas. Indivíduos zigóticos obtidos por autofecundação de 'Sunki', identificados por segregação dePrx, 1 , também apresentaram esse padrāo de duas bandas para Got-2, à semelhança do observado com 'Clementina'. Esses resultados não constituem, entretanto, evidências que Got-2 é um loco duplicado, mas apenas que dois locos em homozigose estāo envolvidos e que, realmente, heterodímeros interlocos nāo se formam. Se esses dois locosfossem independentes, ter-se-ia exatamente o mesmo padrāo observado na progênie de 'Sunki' e o que foi relatado para 'Clementina'.

$\mathrm{Na}$ laranja-azeda, que tem um padrão de três bandas, estão envolvidos também os alelos $F$ e $M$ como em 'Sunki' e 'Clementina'. Neste caso, porém, F, em pelo menos um dos locos, é alelo de $M$. A evidência que nesse clone o alelo M está associado aF em um dos locos, é que gel de tecido somático, como folha, apresenta três bandas, enquanto gel de gräos de pólen, da mesma planta, apresenta somente duas, faltando a banda intermediária, a qual seria o heterodímero intraloco.

O limão-cravo, aqui interpretado como sendo de genótipo FS/MM, por autofecundaçāo originou 83 plantas zigóticas (inequivocamente identificadas por outıos sistemas isoenzímicos) de fenótipos que puderam ser claramente interpretados como de genótipo FF/MM, FS/MM e SS/MM, na proporção de 1:2:1 ( $\left.\chi^{2}=1,19 n s\right)$. Isso mostra que, no limāo-cravo, $F$ é alelo de $S$ em um loco e o outro loco é 
homozigoto MM. Esse resultado evidencia que realmente existem dois locos na regiāo de Got-2. Apesar de um deles estar em heterozigose, o fenótipo visualizado no gel seria também o mesmo se Got-2 correspondesse a um loco duplicado ou a dois locos independentes.

Nenhum dos resultados apresentados aqui ou na literatura realmente prova a validade da hipótese de SOOST \& TORRES (1982). A interpretaçāo definitiva depende da análise genética em progênies de autofecundação ou de cruzamentos envolvendo indivíduos heterozigotos para ambos os locos, com a complicaçăo adicional se se considerar que esses dois locos, caso duplicados, poderiam se apresentar na disposição cis ou trans.

Considerando-se a autofecundação de um indivíduo de genótipo duplamente heterozigoto FM, se Got-2 fosse um loco duplicado, na disposição cis, a progênie visualizada no gel seria constituída de: indivíduos com uma banda avançada (genótipo FF/FF); indivíduos com três bandas, uma avançada, uma retardada e o heterodímero (genótipo $\mathrm{FM} / \mathrm{FM}$ ), e indivíduos com uma banda retardada (genótipo $M M / M M$ ), respectivamente, na proporçāo de 1:2:1. Se estivesse em trans, naprogênie encontrar-se-iam individuos com duas bandas (FF/MM eMM) FF) e indivíduos com três bandas (FM/MF) na proporçăo 1:1. Altemativamente, caso fossem dois locos independentes, a progênie seria constituída de: indivíduos com uma banda avançada (FF FF); indivíduos com uma banda retardada (MMMM); indivíduos com duas bandas, uma avançada e uma retardada (FF MM e MM FF), e indivíduos com três bandas (doze diferentes genótipos heterozigotos para, pelo menos, um loco), ocorrendo, respectivamente, na proporçāo de 1:1:2:12. Estudos a esse respeito foram iniciados recentemente na Seção de Genética do IAC.

PRX - Atividade de peroxidase nas condiçóes deste trabalho é verificada tanto no ânodo quanto no cátodo.

PRX anódica - Foi estudada por IGLESIAS et al. (1974); BUTTON et al. (1976); ESEN \& SOOST (1976); SPIEGEL-ROY et al. (1977); LLANOS \& LIMA (1981) e GERACl et al. (1981) em gel de poliacrilamida, principalmente com respeito a sua utilização na distinção de plantas zigóticas e nucelares comparando-se os diferentes zimogramas.

A única mençāo sobre locos e alelos desta regiāo é feita no trabalho de MOORE \& CASTLE (1988) em gel de amido. Determinaram Prx -1 codificando uma enzima monômera com três alelos $F$ (Rf 0,58 ), M (Rf 0,52 ) e $S(R t 0,49$ ), caracterizando quinze diferentes porta-enxertos. Salientaram o potencial de PRX na distinçāo entre plantas zigóticas e nucelares em cinco dessas quinze populaçōes.

Nas condiçōes do presente trabalho, verificaram-se esses três alelos para $P R X$ anódica. O alelo $\mathrm{F}$ é comum ao germoplasma analisado, não se restringindo particularmente a nenhum grupo. Nesse germoplasma, o $S$ foi encontrado apenas 
em laranja-azeda, associado a $F$, e $\circ \mathrm{M}$ foi observado em homozigose no limāo-cravo e na tangerina 'Ponkan' e, associado ao $F$, em alguns outros clones de tangerinas (Figura 2, Quadro 1).

Esse loco apresenta bom potencial para a identificaçāo de híbridos quando se consideram cruzamentos entre porta-enxertos e de tangerinas com laranjas. Não é adequado, porém, para híbridos entre laranjas-doces, uma vez que esse grupo é monomórfico para o alelo $F$.

$P R X$ catódica - Informaçóes sobre $P R X$ catódica em géis de amido ou mesmo sobre a genética desse sistema sāo inexistentes na literatura.

O sistema foi analisado por SPIEGEL-ROY et al. (1977) e GERACl et al. (1981), em gel de poliacrilamida utilizando tecidos de raiz, e mostrou-se inadequado na distinçăo de clones devido à complexidade dos zimogramas e inconstância dos padrōes.

Realmente, a expressăo de PRX catódica mostra-se sensível não somente a variaçōes de $\mathrm{pH}$ do gel e tempo de corrida como ao estado fisiológico dos seedlings. Verifica-se, em geral, a ocorrência de diversas bandas com nitidez e intensidade de coloração diferentes. Nos seedlings com menos de 60 dias de idade, observa-se que certas plantas não expressam algumas bandas, vindo, porém, a expressá-las uniformemente $\theta$, em posiçōes constantes, aos 120 ou mais dias de idade, podendo então ser empregadas na distinçäo de híbridos. Em folhas de plantas adultas, tais bandas têm uma expressão uniforme e migração relativa entre si constante, podendo ser utilizadas para a caracterização de clones (Figura 2).

A interpretaçăo genética dessas bandas de PRX catódica não foi ainda realizada extensivamente, razăo pela qual são indicados somente os padrōes dos clones com os Rfs das bandas observadas, nảo thes tendo sido atribuída nomenclatura genética - Figura 3. Os dados até o presente indicam que a banda de Rf 0,17 , presente na tangerina 'Sunki' e no trifoliata 'Davis $A$ ', parece ser condicionada por um loco em homozigose. Híbridos 'Davis A' e 'Sunki', identificados por Got-1, Aps-1 e Me-1, invariavelmente apresentam também a mesma banda. No trifoliata 'Davis $A$ ', caracteristicamente, duas outras bandas de Rfs, $-0,25$ e $-0,32$, são observadas $e$, aparentemente, pertencem a outro loco, heterozigoto, codificando para uma enzima monômera. Nos mesmos híbridos 'Davis A' x 'Sunki', alguns indivíduos apresentam a banda retardada (Rf $-0,32)$ e outros, a banda mais avançada (Rf $-0,25)$ de $P$. trifoliata.

Apesar de a interpretaçāo genética não estar ainda concluída, é evidente o potencial desse sistema na identificaçăo de híbridos, visto a variabilidade observada e constância dos padrōes. 


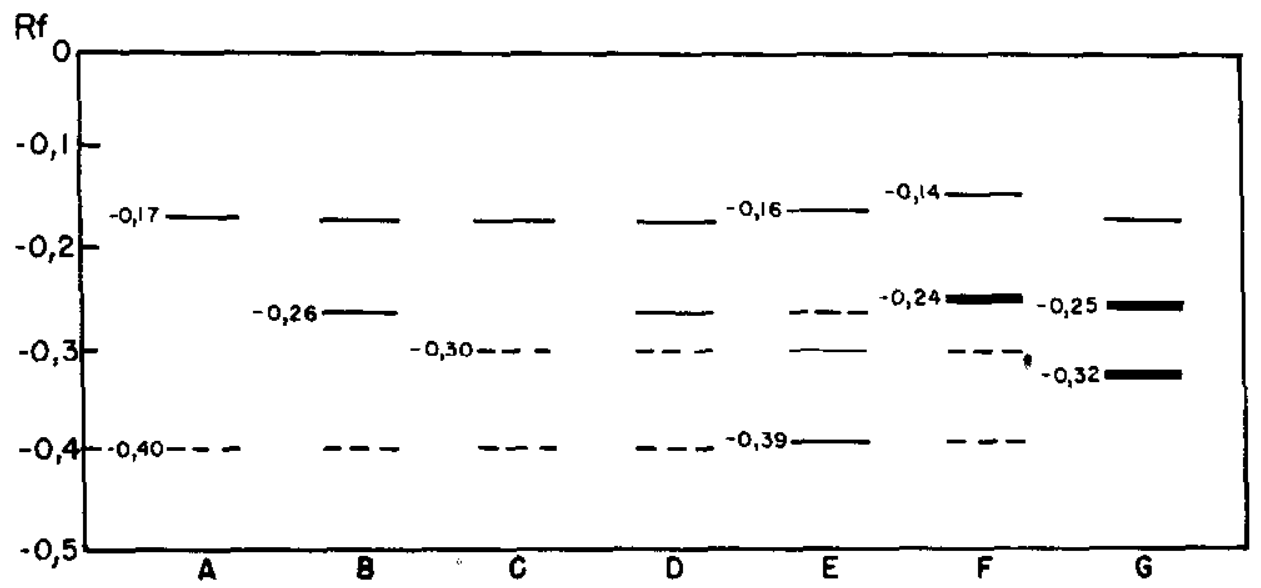

FIGURA 3. Padröes isoenźmicos (A-G), intensidade relativa e Rfs observados para o sistema de PRX catódica nos diversos ctones estudados.
A: Fremont, Sunki, tangerina'Cravo';
B: Carvalhaes, Cleópatra, Dancy, Nova, Osceola, Ponkan;
C: Hamlin, Hansen, Lima graúda, Mortera, Natal, Paraguai, Pêra, Satsuma, Valência folha murcha, Vermelha, Westin;
D: Clementina, Kara, King, Lee, Mel, Murcote;
E: Limäo-cravo Lumeira;
F: Laranja-azeda Săo Paulo;
G: Trifoliata Davis A.

\subsection{Utilizações das análises genéticas}

O conhecimento e a análise genética de clones de citros têm importantes implicaçóes não-somente no melhoramento genético como em outros aspectos práticos da citricultura.

Com relaçáo ao melhoramento, um dos problemas existentes é a poliembrionia. Quandoserealizam cruzamentos controlados, as progênies resultantes constituemuma mistura de individuos híbridos e de clones nucelares geneticamente idênticos ao genitor feminino. A caracterização dos clones pelos padrōes de isoenzimas $\theta$ a determinaçăo dos genótipos dos diversos locos aqui pesquisados sāo a base para a identificação de híbridos. $O$ potencial de cada loco, quando analisado separadamente, já foi discutido na seçāo anterior, podendo variar de 0 a $100 \%$, de acordo com o cruzamento específico. Como a distinçāo dos híbridos, em muitos casos, pode ser feita através de mais de um loco, a eficiência desse método é bastante aumentada, como explicado a seguir.

Exemplificando, supondo-se o cruzamento de um clone A como genitor feminino de genótipo FS, FS, FS/MM, MM, FF, com um clone $B$ de genótipo FF, SS, FF/MM, FF FF, respectivamente, para os locos Pgi-1, Got-1, Got-2, Prx, -1 e Pgm-1. Por PGM, não seria possível reconhecer híbridos pelo fato de serem ambos os 
genitores FF. Baseando-se em cada um dos demais locos, separadamente, distinguir-se-ia apenas metade dos híbridos, os quais seriam, respectivamente, para esses locos, aqueles de genótipo FF, SS, FF/MM e FM, pois os híbridos possuindo os genótipos alternativos FS, FS, FS/MM e MM seriam indistinguíveis dos genótipos nucelares. No entanto, quando esses quatro primeiros locos são analisados conjuntamente, a probabilidade de que um híbrido nāo seja identificado corresponde à probabilidade da ocorrência simultânea daqueles quatro genótipos alternativos idênticos aos maternais, ou seja, (1/2) 4 . Em outras palavras, para esse cruzamento, tem-se a possibilidade de identificar $93,75 \%$ dos híbridos obtidos e separá-lospara estudos posteriores, descartando-se apenas $6,25 \%$ deles juntamente com os nucelares.

Essa grande eficiência na identificação reside, portanto, no fato de a análise basear-se no genótipo de vários locos. O método aqui desenvolvido apresenta ainda a vantagem operacional de determinar, simultaneamente, todos esses genótipos numa mesma corrida. Isso é possível porque os vários sistemas isoenzímicos săo satisfatoriamente resolvidos numa mesma condiçāo eletroforética e cada gel pode ser seccionado horizontalmente em até sete camadas.

Cabe chamar a atençāo que as consideraçōes acima se referem exclusivamente à eficiência da eletroforese na identificação dos híbridos obtidos, nada tendo a ver com a porcentagem de híbridos produzidos em cada cruzamento. Esta, por sua vez, depende dos genitores envolvidos e de suas características, como grau de compatibilidade, viabilidade do zigoto e taxa de embrionia.

A identificaçāo de híbridos é de extrema valia para o melhoramento de espécies perenes como o Citrus. Para qualquer programa de melhoramento, existe uma limitação prática e econômica quanto ao número de indivíduos a serem mantidos no campo durante vários anos. É evidente o valor dessa identificaçāo precoce, pois as avaliaçōes agronômicas poderăo ser realizadas em lotes experimentais constituídos apenas de individuos sabidamente híbridos, visto que os nucelares são descartados antes do plantio no campo.

Outra aplicaçăo imediata da eletroforese se refere à identificaçăo de indivíduos zigóticos em progênies de autofecundação ou cruzamentos controlados para estudos básicos sobre herança da resistência a doenças ou de outros caracteres agronômicos.

Um aspecto de grande importância prática se refere aos estudos da biologia da reproduçāo, nāo-somente dos futuros porta-enxertos resultantes do programa de melhoramento como daqueles já comumente utilizados em nossas lavouras.

Embora a ocorrência da embrionia nucelar seja um problema para o melhoramento, o emprego extensivo de porta-enxertos nas lavouras cítricas depende, no entanto, da sua alta freqüência. 
Raramente sāo realizados experimentos para determinar a porcentagem exata de clones nucelares em progênies de polinizaçăo aberta de porta-enxertos, devido ao espaço e tempo necessários para a identíficaçăo inequívoca dos nucelares pelas características de seus frutos em plantas adultas. É comum admitir que um alto grau de poliembrionia implica uma alta proporçăo de seedlings nucelares e que seedlings zigóticos podem ser morfologicamente identificados principalmente pelo tamanho discrepante das plantas na sementeira. Esse procedimento, embora prático, não fornece indicaçōes seguras sobre a porcentagem de seedlings nucelares. Para alguns porta-enxertos, a distinção morfológica é eficiente, mas, para outros, é extremamente falha, como, por exemplo, no limão 'Volkamericano' e $P$. trifoliata, nos quais os seedlings zigóticos, identificados através da análise de isoenzimas, são morfologicamente semelhantes aos nucelares (MOORE \& CASTLE, 1988).

Para os clones de porta-enxerto extensivamente utilizados no Brasil, não se têm informaçóes a esse respeito. Tais pesquisas foram recentemente iniciadas.

\section{CONCLUSÕES}

1) As folhas de seedlings constituem um tecido apropriado para análise de isoenzimas de citros, visto que seus padrōes são os mesmos das plantas adultas. $A$ análise de isoenzimas permite uma identificaçăo precoce dos híbridos, clones nucelares e produtos de autofecundaçăo.

2) No preparo das amostras para eletroforese, bastam $60 \mathrm{mg}$ de tecido de folhas. É desnecessária a utilizaçāo de extratores especiais,pois bons resultados sáo obtidos com $0,2 \mathrm{ml}$ de água destilada. A adição de $7 \mathrm{mg}$ de sílica lavada, por amostra, facilita o processo de maceraçāo e nāo altera a resolução de bandas.

3) A utilizaçăo de TRIS $(0,015 \mathrm{M})$-citrato $(0,036 \mathrm{M}) \mathrm{pH} 8,0-8,3$ para o gel e ácido bórico $(0,3 \mathrm{M}) \mathrm{pH} 8,3$ para os eletrodos permitiu a resoluçăo simultânea dos locos Pgi-1, Got-1, Got-2, Aps-1, Pgm-1, Me-1, Prx -1 e PRX catódica, numa mesma corrida, efetuada a $300 \mathrm{~V}$, sem ultrapassar $30 \mathrm{~mA}$. Com o sistema utilizado, até sete camadas podem ser obtidas de um único gel.

4) Em alguns cruzamentos, a identificação dos híbridos pôde ser feita combase em apenas um loco. Em outros, a análise conjunta de sistemas aumentou a eficiência do método por diminuir a probabilidade que seedlings zigóticos tenham os mesmos genótipos heterozigotos dos nucelares para vários locos.

5) Definiu-se o loco Aps-1, até então desconhecido. P. trifoliata 'Davis A'possui um alelo nulo, recessivo. Os demais clones analisados possuem o alelo $C$. Aps-1 constitui ótimo sistema para identificaçăo de híbridos desse clone como genitor feminino. 
6) PRX catódica, ainda nāo geneticamente caracterizada, parece ser codificada por mais de um loco que se expressa uniformemente em folhas de plantas adultas e em seedlings com 120 ou mais dias de idade. A ampla variabilidade e aparente segregação em cruzamentos sugerem sua utilização na identificação de híbridos. Entre os 31 clones estudados, sete padrōes distintos foram observados.

7) Um novo alelo para Got-2 é descrito. Denominado I, tem migração intermediária entre os alelos $F$ e $M$, sendo encontrado nas laranjas-doces e na tangerina 'Cravo'. Dois locos, duplicados ou independentes, codificam para Got-2. No limão-cravo, um dos locos é homozigoto MM, cujo homodímero tem a mesma migraçāo do heterodímero entre os alelos $F$ e $S$ do outro loco. Na laranja-azeda, um dos locos é provavelmente homozigoto $M M$, porém é certo que o outro loco é heterozigoto FM. Somente heterodímero intraloco é formado e se encontra ausente em preparaçōes de tecido haplóide dos grãos de pólen.

8) Trinta e um clones de possível interesse para o melhoramento foram caracterizados isoenzimicamente. Vários deles haviam sido também referidos na literatura. Embora a maioria tenha tido seus genótipos confirmados, alguns clones do germoplasma analisado são geneticamente distintos, teoricamente possíveis de ser obtidos através de recombinaçāo genética por autofecundaçāo, o que sugere uma origem zigótica dessas introduçōes.

\section{REFERÊNCIAS BIBLIOGRÁFICAS}

ARULSEKAR, S.; PARFITT, D.E.; BERES, W. \& HANSCHE, P.E. Genetics of malate dehydrogenase isozymes in peach. Journal of Heredity, Washington, 77(1):49-51, 1986.

\& MCGRANAHAN, G.H. Isozyme gene markers in Juglans species: inheritance of GPI and AAT in J. regia and J. hindsii. Journal of Heredity, Washington, 76(2):103-106, 1985.

BRINGHURST, R.S.; ARULSEKAR, S.; HANCOCK JUNIOR, J.F. \& VOTH, V. Electrophoretic characterization of strawberry cultivars. Journal of the American Society ofr Horticultural Science, Alexandria, 106(5):684-687, 1981.

BUTTON, J.; VARDI, A. \& SPIEGEL-ROY, P. Root Peroxidase isoenzymes as an aid in Citrus breeding and taxonomy. Theoretical and Applied Genetics, Berlin, 47:119-123, 1976.

BYRNE, D.H. \& LITTLETON, T.G. Characterization of isozyme variability in apricots. Journal of the American Society for Horticultural Science, Alexandria 114(4):674-678, 1989.

\& - Electrophoretic characterization of diploid plums of the southeastern United States. Journal of the American Society for Horticuttura/ Science, Alexandria, 113(6):919-924, 1988. 
CAMERON, J.W. \& FROST, H.B. Genetics, breeding, and nucellar embryony. In: REUTHER, W., BATCHELOR, L.D. \& WEBBER, H.J., eds. The citrus industry. v.ll. Anatomy, physiology, genetics, and reproduction. Riverside, University of CaliforniaDivision of Agricultural Science, 1968. cap.5, p.325-370.

ESEN, A \& SOOST, R.K. Peroxidase polymorphism in Citrus. Joumal of Heredity, Washington, 67(4): 199-203, 1976.

FAO TRADE YEARBOOK. Rome, FAO, v.42, 1988.

GERACI, G.; MANZOCCHI, L.A.; TUSA, N.; OCCORSO, G.; RADOGNA, L. \& DE PASQUALE, F. Comparison of different methods for identifying zygotic and nucellar seedlings in Citrus. In: INTERNATIONAL SOCIETY OF CITRICULTURE, 5. TOKYO, 1981. Proceedings. Tokyo, 1982. v.1, p.1-4.

HAUAGGE, R.; KESTER, D.E.; ARULSEKAR, S.; PARFITT, D.E. \& LIU, L. Isozyme variation among Califomia almond cultivars: II. Cultivar characterization and origins. Joumal of the American Society for Horticultural Science, Alexandria, 112(4):693-698, 1987.

IGLESIAS, L.; LIMA, H. \& SIMON, J.P. Isoenzyme identification of zygotic and nucellar seedlings in Citrus. Joumal of Heredity, Washington, 65(2):81-84, 1974.

LLANOS, J.L. \& H. LIMA. Peroxidase in healthy grapefruit trees and those affected by blight. In: INTERNATIONAL SOCIETY OF CITRICULTURE, 5., Tokyo, 1981. Proceedings. Tokyo, 1982. v.1, p.476-478.

LOUKAS, M.;STAVPAKAKIS, M.N. \& KIMBRAS, C.B. Inheritance of polymorphic isoenzymes in grape cultivars. Journal of Heredity, Washington, 74(3):181-183, 1983.

MANSHARDT, R.M. \& WENSLAFF, T.F. Zygotic polyembryony in interspecific hybrids of Carica papaya and C. caulifora. Joumal of the American Society for Horticultural Science, Alexandria, 114(4):684-689, 1989.

MEDINA FILHO, 4.P. Eletroforese em gel de amido: aplicaçóes em genética e melhoramento de plantas. Campinas, Instituto Agronômico. 1983. 15p. (Circular, 121)

\& BALLVE, R.M.L. Protocolo laboratorial para preparaçáo e corrida de géis de amido e revelação para isoenzimas vegetais. In: CURSO TEÓRICO-PRÁTICODE ELETROFORESE, 5., Nova Odessa, 1989. Nova Odessa, Instituto de Zootecnia, 1989. 59p.

MOORE, G.A \& CASTLE, W.S. Morphological and isozymic analysis of open-pollinated Citrus rootstock population. Journal of Heredity, Washington, 79(1):5963, 1988.

PARFITT,D.E.;ARULSEKAR, S. \& RAMMING, D.W. Identification of plum $x$ peach hybrids by isoenzyme analysis. HortScience, Alexandria, 20(2):246-248, 1985.

ROOSE, M.L. Isozymes and DNA restriction fragment length polymorphisms in citrus breeding and systematics. In: INTERNATIONAL CITRUS CONGRESS, 6., Tel Aviv, 1988. Proceedings. Philadelphia Rehovot, Balaban, 1988. p.155-165.

\& TRAUGH, S.N. Identification and performance of citrus trees on nucellar and zygotic rootstocks. Journal of the American Society for Horticultural Science, Alexandria, 113(1):100-105, 1988. 
SHAW, C.R. \& PRASAD, R. Starch gel eletrophoresis of enzymes: a compilation of recipes. Biochemical Genetics, New York, 4:297-320, 1970.

SOOST, R.K. \& CAMERON, J.W. Citrus. In: JANICK, J. \& MOORE, J.N., eds. Advances in fruit breeding. West Lafayette, Purdue University Press, 1975. p.507-540.

\& TORRES, AM. Leaf isozymes as genetic markers in Citrus. In: INTERNATIONAL SOCIETY OF CITRICULTURE, 5., Tokyo, 1981. Proceedings. Tokyo, 1982. v.1, p.7-10.

SPIEGEL-ROY, P.; VAFDI, A. \& SHANI, A. Peroxidase isozymes as a tool for early separation of nucellar and zygotic citrus seedlings. In: INTERNATIONAL SOCIETY OF CITRICUTURE, 3., Orlando, 1977. Proceedings. Orlando, 1977. v.2, p.619-624.

TANAKA, T. Species problem in citrus: a critical study of wild and cultivated units of Citrus, based upon field studies in their native homes. Tokyo, Japanese Society for the Promotion of Science, 1954. 152p.

TANKSLEY, S.D. An efficient and economical design for starch gel electrophoresis. Report of the Tomato Genetics Cooperative, Davis (29):37-38, 1979.

-; MEDINA FILHO, H.P. \& RICK, C.M. The effect of isozyme selection on metric characters in an interspecific backcross of tomato: basis of an early screening procedure. Theoretical and Applied Genetics, Berlin, 60:291-296, 1981.

$\&$

Use of naturally-occurring enzyme variation to detect and map genes controlling quantitative traits in an interspecific backcross of tomato. Heredity, London, 49(1):11-25, 1982.

TORRES, A.M.; DIEDENHOFEN, U.;BERGH, B.O. \& KNIGHT, R.J. Enzyme polymorphisms as genetic markers in the avocado. American Journal of Botany, Baltimore, 65(2):134$139,1978 a$.

;MAU-LASTOVICKA, T.;WILLIAMS, T.E. \& SOOST, R.K. Segregation distortion and linkage of Citrus and Poncirus isozyme genes. Journal of Heredity, Washington, 76(4):289-294, 1985.

;SOOST, R.K. \& DIEDENHOFEN, U. Leat isozymes as genetic markers in Citrus. American Journal of Botany, Baltimore, 65(8):869-881, $1978 \mathrm{~b}$.

ing nucellar from zygotic seedlings. Joumal of Heredity, Washington, 73(5):335-339, 1982.

VALLEJOS, C.E. Enzyme activity staining. In: TANKSLEY, S.D. \& ORTON, T.J., eds. Isozymes in plant genetics and breeding: part A. Amsterdam, Elsevier, 1983. p.469516.

WEEDEN, N.F. \& LAMB, R.C. Identification of apple cultivars by isozyme phenotypes. Journal of the American Society for Horticultural Science, Alexandria, 110(4):509-515, 1985. 